\title{
Glucose and fructose utilization by rat spermatozoa within the uterine lumen
}

\author{
H. J. Leese, N. R. Astley and D. Lambert \\ Department of Biology, University of York, York YOI 5DD, U.K.
}

\begin{abstract}
Summary. Concentrations of glucose, fructose and spermatozoa in the lumen of the rat uterus were measured at intervals after mating with fertile or vasectomized males. The results suggest that rat spermatozoa within the uterus utilize both glucose and fructose, and that the glucose is used preferentially.
\end{abstract}

\section{Introduction}

The principal metabolizable sugar in mammalian semen is fructose, which numerous in-vitro studies have shown may be utilized aerobically and anaerobically by spermatozoa (Mann, 1964). Fructose is probably of greatest value at the site of semen deposition in the female reproductive tract, where the sperm density is high and the oxygen tension low, but direct evidence for the utilization of fructose in the female tract after mating is lacking. The rat is a convenient animal in which to investigate this phenomenon, since the semen is deposited predominantly in the uterus. The concentrations of fructose and spermatozoa in the rat uterus after mating were therefore measured. Since glucose is readily secreted into the perfused rat uterine lumen (Leese, Aldridge \& Kiernan, 1979), the concentration of this sugar was also measured.

\section{Materials and Methods}

Female and male rats (Wistar 200-250 g) were housed individually in a room in which the normal day/night cycle was reversed, artificial light being provided from 18:00 until 06:00 h. Mating experiments were carried out under a red safety light, usually between 10:00 and 12:00 h. Vaginal smears were taken to assess whether a given female was in oestrus, but vasectomized males were also used to test the lordosis response. A receptive female was transferred to a male of proven fertility. Normally, the male would mount the female about 20 times over a period of about $30 \mathrm{~min}$ before copulation with ejaculation occurred. The female was then taken from the male's cage. At intervals after mating, the fèmales were anaesthetized with ether and a sample of the contents of each uterine horn was withdrawn into a syringe. In some experiments, the contents of both horns were withdrawn together; in others, they were withdrawn at different intervals, with the animals maintained under anaesthesia. The volume of uterine fluid was not measured accurately, but usually ranged from 200 to $400 \mu$ l. Samples of uterine fluid were also taken from oestrous females that had not been mated. Samples $(50 \mu l)$ of the fluid were deproteinized with $0.6 \mathrm{M}-\mathrm{HClO}_{4}$, the supernatants neutralized with $5 \mathrm{M}-\mathrm{KOH}$ and analysed for glucose and fructose, in the same cuvette, by the method of Bernt \& Bergmeyer (1974). Further samples $(10 \mu \mathrm{l})$ of the uterine fluid were added to $1 \mathrm{ml}$ formal-saline and the sperm concentration was measured with a haemocytometer, sometimes after further dilution. Male rats of proven fertility were vasectomized under ether anaesthesia and mated with receptive females as described above. 


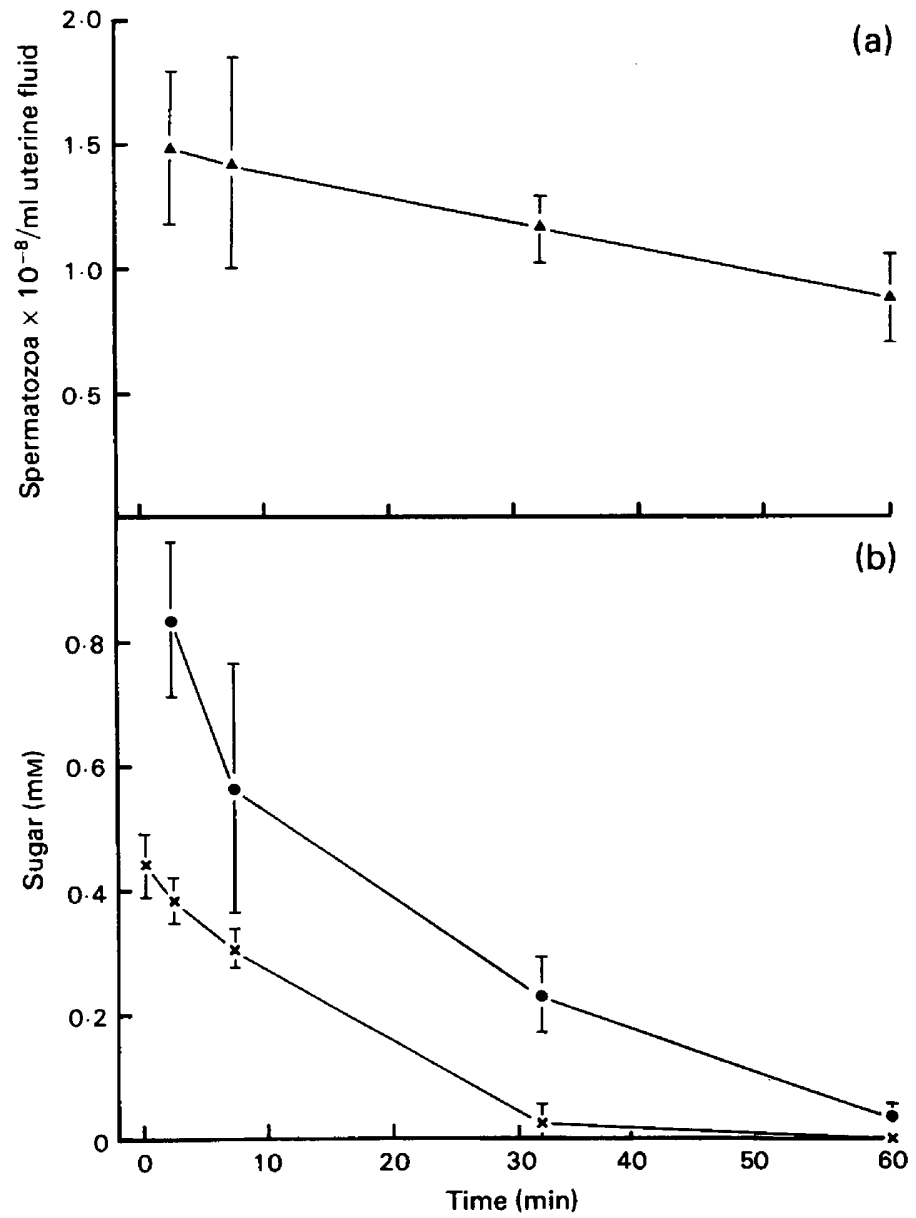

Text-fig. 1. The concentration of (a) spermatozoa $(\Delta)$ and (b) fructose $(0)$ and glucose $(x)$ in the rat uterine lumen at various intervals after mating with normal male rats. Values are mean \pm s.e.m. of at least 4 determinations.

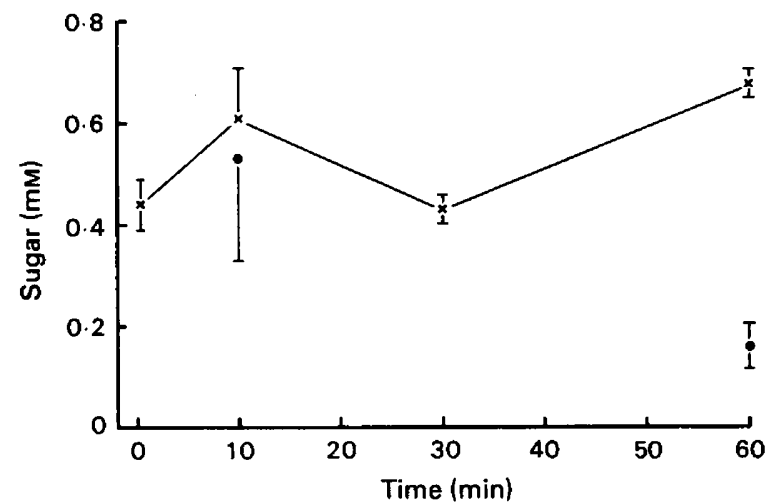

Text-fig. 2. The concentration of fructose $(e)$ and glucose $(x)$ in the rat uterine lumen at various intervals after mating with vasectomized males. Values are mean \pm s.e.m. of at least 6 determinations. Fructose concentrations were not determined at $30 \mathrm{~min}$ post coitum. 


\section{Results}

The concentration of fructose in the uterus of females mated with fertile males declined steadily post coitum to reach very low levels after $1 \mathrm{~h}$ (Text-fig. 1b). Sperm concentration also declined (Text-fig. 1a). However, glucose declined rapidly and had almost totally disappeared by $30 \mathrm{~min}$ after mating (Text-fig. 1b). In contrast, the concentration of glucose in the uterus of females mated with vasectomized males remained at or above the concentration before mating (Text-fig. 2 ). The fructose concentration in these experiments also fell, although less markedly than in the presence of spermatozoa.

\section{Discussion}

These results indicate that glucose disappears as rapidly as fructose in the presence, but not in the absence, of spermatozoa in the rat uterus, whereas a large proportion of the fructose disappearance occurred in the absence of spermatozoa. Taken together, the results suggest that spermatozoa utilize both glucose and fructose within the rat uterus and that in all probability glucose is used preferentially. This conclusion is supported by three in-vitro studies which showed that ram, bull and cock spermatozoa utilized glucose preferentially when it was presented as an equimolar mixture with fructose (Mann, 1951; van Tienhoven, Salisbury, VanDemark \& Hansen, 1952; van Tienhoven, 1960).

The question arises as to whether glucose and fructose are metabolized aerobically or anaerobically by spermatozoa within the rat uterus. We are unaware of any values of the $\mathrm{ZO}_{2}$ of rat spermatozoa, but assuming this to be of the same order as in related species (i.e. approximately $20 \mu \mathrm{l} / 10^{8} \mathrm{spermatozoa} / \mathrm{h}$ at $37^{\circ} \mathrm{C}$ ), and further assuming that the volume of uterine fluid is $400 \mu \mathrm{l}$ and the total sperm number $6 \times 10^{7}$, it may be calculated that $0.045 \mu \mathrm{mol}$ hexose could be consumed aerobically in $30 \mathrm{~min}$. The glucose disappearance from the uterine lumen during this time was $0.16 \mu \mathrm{mol}$, suggesting that a considerable fraction of the hexose available to spermatozoa in the uterus is consumed anaerobically. The appreciable disappearance of fructose in the absence of spermatozoa may be explained by its diffusion down the steep concentration gradient which will exist for this sugar between the uterine lumen, the cells of the endometrium and the blood. Some of the fructose may also be metabolized by the uterus before it reaches the circulation.

In addition to highlighting the potential role of glucose to sperm survival, our approach gives direct information on the metabolism of spermatozoa in the uterus, and may be applicable to the study of gamete metabolism in other species and at different sites within the female tract.

\section{References}

Bernt, E. \& Bergmeyer, H.-U. (1974) D-fructose. In Methods of Enzymatic Analysis, 2nd English edn, Vol. 3, pp. 1304-1307. Ed. H.-U. Bergmeyer. Academic Press, New York.

Leese, H.J., Aldridge, S. \& Kiernan, T. (1979) Glucose movement into rat uterine fluid. J. Reprod. Fert. 56, 615-618.

Mann, T. (1951) Mammalian Semen: composition, metabolism and survival. Biochem. Soc. Symp. 7, $11-22$.
Mann, T. (1964) The Biochemistry of Semen and of the Male Reproductive Tract. Methuen, London.

van Tienhoven, A. (1960) The metabolism of fowl sperm in different diluents. J. agric. Sci., Camb. 54, 67-80.

van Tienhoven, A., Salisbury, G.W., VanDemark, N.L. \& Hansen, R.G. (1952) The preferential utilization by bull spermatozoa of glucose as compared to fructose. J. Dairy Sci. 35, 637-641.

Received 27 June 1980 